\title{
EphA3 inhibits migration and invasion of esophageal cancer cells by activating the mesenchymal-epithelial transition process
}

\author{
XIA CHEN $^{1,2}$, BIN LU $^{2,3}$, QIAN MA ${ }^{2}$, CHENG-DONG JI ${ }^{4}$ and JIAN-ZHONG LI ${ }^{3}$ \\ ${ }^{1}$ Key Laboratory, Yangpu Hospital, Tongji University School of Medicine, Shanghai 200090; \\ ${ }^{2}$ International Joint Cancer Institute; ${ }^{3}$ Department of Biochemical Pharmacy, \\ Second Military Medical University, Shanghai 200433; ${ }^{4}$ Department of Scientific Research Management, \\ Yangpu Hospital, Tongji University School of Medicine, Shanghai 200090, P.R. China
}

Received June 13, 2018; Accepted November 2, 2018

DOI: 10.3892/ijo.2018.4639

\begin{abstract}
Eph receptor tyrosine kinases are critical for cell-cell communication during normal and oncogenic development. Eph receptor A3 (EphA3) expression is associated with tumor promotion in certain types of cancer; however, it acts as a tumor suppressor in others. The expression levels of EphA3 and its effects on tumor progression in esophageal squamous cell carcinoma (ESCC) cell lines were determined using reverse transcription-quantitative polymerase chain reaction analysis and a Transwell invasion assay. The present study demonstrated that EphA3 expression was decreased in ESCC tissues and cell lines. Treatment with the DNA methylation inhibitor 5-aza-2'-deoxycytidine increased the mRNA expression levels of EphA3 in the ESCC cell lines KYSE510 and KYSE30. In addition, overexpression of EphA3 in KYSE450 and KYSE510 cells inhibited cell migration and invasion. EphA3 overexpression also decreased RhoA GTPase. Furthermore, EphA3 overexpression induced mesenchymal-epithelial transition, as demonstrated by epithelial-like morphological alterations, increased expression of epithelial proteins (E-cadherin and the tight junction protein 1 zonula occludens-1) and decreased expression of mesenchymal proteins (Vimentin, N-cadherin and Snail). Conversely, silencing EphA3 in KYSE410 cells triggered epithelial-mesenchymal transition, and promoted cell migration and invasion. These results suggested that EphA3 may serve a tumor-suppressor role in ESCC.
\end{abstract}

Correspondence to: Dr Xia Chen, Key Laboratory, Yangpu Hospital, Tongji University School of Medicine, 450 Tengyue Road, Shanghai 200090, P.R. China

E-mail: chenxxchen@hotmail.com

Professor Jian-Zhong Li, Department of Biochemical Pharmacy, Second Military Medical University, 325 Guohe Road, Shanghai 200433, P.R. China

E-mail: lijianzhong1234@hotmail.com

Key words: EphA3, esophageal squamous cell carcinoma, mesenchymal-epithelial transition, metastasis

\section{Introduction}

Esophageal cancer is the eighth most prevalent type of cancer worldwide $(1,2)$, of which, esophageal squamous cell carcinoma (ESCC) is a predominant histological type (3). Despite advances in diagnostic tools, surgical techniques and chemotherapy over the past few decades, the 5-year survival rate for patients with esophageal cancer ranges between 15 and 20\% (4). Therefore, novel diagnostic tools, therapeutic strategies and molecular prognostic markers are urgently required for this disease.

Eph receptors are the largest known family of receptor tyrosine kinases, which participate in vital functions, including cell migration and axon guidance during development and homeostasis (5). Eph receptors and ephrin ligands tend to be highly expressed during development. In addition, Eph receptors have been reported to be aberrantly expressed in numerous types of cancer (6-8). Epithelial-mesenchymal transition (EMT) is an evolutionarily conserved developmental process, during which epithelial cells lose polarity and develop a mesenchymal phenotype. EMT progression triggers the dissociation of carcinoma cells from the primary tumor; these cells subsequently migrate and disseminate to distant sites (9). Eph receptor A3 (EphA3) is a member of the Eph family of receptors, which is highly expressed in embryonic tissues $(10,11)$ and appears to serve a critical role in EMT (12). Overexpression of EphA3 has been detected in some types of cancer, including lung cancer, leukemia, melanoma, lymphoma and gastric carcinoma (10,13-16). Conversely, EphA3 mutations have also been identified, thus suggesting a tumor-suppressor role for EphA3 in other types of cancer, including breast, colorectal and lung cancer (17-19). Although EphA3 deletions have been identified in patients with ESCC and in ESCC cell lines $(20,21)$, the role of EphA3 in ESCC remains unknown.

The present study aimed to investigate the expression levels and functions of EphA3 in ESCC. The results indicated that the expression levels of EphA3 were decreased in ESCC, and its forced overexpression in the ESCC cells (KYSE450 and KYSE510) triggered mesenchymal-epithelial transition (MET), and inhibited cell migration and invasion. These results suggested that EphA3 may serve a tumor-suppressor role in ESCC. 


\section{Materials and methods}

Reagents and tissues. $\beta$-actin mouse monoclonal (cat. no. sc-130065) and EphA3 rabbit polyclonal antibodies (cat. no. sc-919) were obtained from Santa Cruz Biotechnology, Inc. (Dallas, TX, USA). RhoA rabbit antibody (cat. no. E11-0568B) was obtained from Enjing Biotech Co., Ltd. (Nanjing, China). Antibodies for zonula occludens (ZO)-1 (cat. no. 5406), Snail (cat. no. 3879), Vimentin (cat. no. 3932), E-cadherin (cat. no. 14472), N-cadherin (cat. no. 14215) and horseradish peroxidase-linked anti-mouse/anti-rabbit immunoglobulin $\mathrm{G}$ (cat. nos. 7076 and 7074) were all purchased from Cell Signaling Technology, Inc. (Danvers, MA, USA). ESCC and adjacent non-cancerous tissue specimens were collected from patients who underwent surgical treatment for ESCC between July 2010 and November 2013 at Changhai Hospital (Shanghai, China). Tissue specimens were obtained from patients who had not received preoperative treatment, such as chemotherapy or radiotherapy. The patients comprised eight men and seven women, with a median age of 62.2 years (range, 52-74 years). The present study was approved by the Ethics Committee of the Second Military Medical University (Shanghai, China). Written informed consent was obtained from each patient. Prior to initiation of the study, histopathological examinations were performed to confirm that there were enough cancer cells in the tumor samples and that no cancer cells contaminated the non-cancerous tissues.

Cell culture. The human ESCC cell lines (KYSE450, KYSE30, KYSE410 and KYSE510) were kindly provided by Professor Tao Qian (Chinese University of Hong Kong, Hong Kong, China). These cells were maintained in Dulbecco's modified Eagle's medium (Gibco; Thermo Fisher Scientific, Inc., Waltham, MA, USA) and RPMI-1640 (Gibco; Thermo Fisher Scientific, Inc.) in a 1:1 ratio, supplemented with $10 \%$ fetal bovine serum (FBS; Sigma-Aldrich; Merck KGaA, Darmstadt, Germany) and $100 \mathrm{U} / \mathrm{ml}$ penicillin, $100 \mu \mathrm{g} / \mathrm{ml}$ streptomycin (Gibco; Thermo Fisher Scientific, Inc.). All cells were cultured in a humidified atmosphere containing $7 \% \mathrm{CO}_{2}$ at $37^{\circ} \mathrm{C}$.

Generation of stable cell lines. For the production of stable cells, the full-length coding sequence of human EphA3 (GenBank accession number, NM_005233; https://www.ncbi. nlm.nih.gov/genbank/) was cloned into Lenti-X lentiviral expression vectors (Clontech Laboratories, Inc., Mountainview, CA, USA). The recombinant lentiviruses or control (empty vector) were then used to infect KYSE450 and KYSE510 cells grown to $30 \%$ confluence at multiplicity of infection 50 . Infected cells were cultured for $24 \mathrm{~h}$ prior to selection using a pre-optimized dose of $2 \mu \mathrm{g} / \mathrm{ml}$ puromycin (Invitrogen; Thermo Fisher Scientific, Inc.) for 2 weeks. Morphological alterations of the infected cells were observed by using an Olympus IX71 fluorescence microscope (Olympus Corporation, Tokyo, Japan).

Plasmid construction. The full-length EphA3 cDNA was cloned into Lenti-X lentiviral expression vectors (Clontech Laboratories, Inc.). Tyrosine residues Y596, Y602, Y779 and lysine residue K653 were mutated using site-directed mutagenesis by overlapping polymerase chain reaction (PCR), as previously described (22). The recombinant lentiviruses were then used to infect KYSE510 cells grown to $30 \%$ confluence at multiplicity of infection 50. Infected cells were cultured for $24 \mathrm{~h}$ at $37^{\circ} \mathrm{C}$ prior to selection using a pre-optimized dose of $2 \mu \mathrm{g} / \mathrm{ml}$ puromycin (Invitrogen; Thermo Fisher Scientific, Inc.) for 2 weeks, in order to generate stably infected cell lines.

EphA3 knockdown by RNA interference. Short hairpin (sh) RNA-mediated EphA3 silencing was performed in KYSE410 cells using BLOCK-iT ${ }^{\mathrm{TM}}$ lentiviral RNAi expression system (Invitrogen; Thermo Fisher Scientific, Inc.) after packaging in 293FT cells (Invitrogen; Thermo Fisher Scientific, Inc.), according to the manufacture's protocol. The recombinant lentiviruses or control were then used to infect KYSE410 cells grown to $30 \%$ confluence at a multiplicity of infection 50 at $37^{\circ} \mathrm{C}$ for $72 \mathrm{~h}$. A respective scramble control shRNA (5'-GAT CCCCGTACGCGGAATACTTCGATTCAAGAGATCGAA GTATTCCGCGTACGTTTTTA-3') was also used. The sequences were as follows: sh1, 5'-GCCCATTTACAGTGAA GAATCcgaaGATTCTTCACTGTAAATGGGC-3'; sh2, 5'-GC AGGTGTGAGAATAATTACTcgaaAGTAATTATTCT CACACCTGC-3'; and sh3, 5'-GGAAAGATGTTACCTTCA ACAcgaaTGTTGAAGGTAACATCTTTCC-3'; lower-case letters indicate linker sequences.

5-Aza-2'-deoxycytidine (5-Aza-dC) treatment. KYSE510 and KYSE30 cell lines were split to obtain cells with a low confluence $(30 \%) 12 \mathrm{~h}$ prior to treatment. Subsequently, cells were treated with 5-Aza-dC (Sigma-Aldrich; Merck KGaA), at a concentration of $5 \mu \mathrm{M}$, in a humidified atmosphere containing $7 \% \mathrm{CO}_{2}$ at $37^{\circ} \mathrm{C}$. All media were replenished daily, and cells were harvested after 3 or 4 days of treatment.

Immunocytochemistry. For immunocytochemistry, cells were grown on coverslips to $80 \%$ confluence and were washed with PBS, fixed with $4 \%$ paraformaldehyde in PBS for 15 min at $4{ }^{\circ} \mathrm{C}$ and permeabilized with $0.2 \%$ Triton $\mathrm{X}-100$ for $10 \mathrm{~min}$ at room temperature. Subsequently, cells were blocked for $60 \mathrm{~min}$ at room temperature in PBS/0.1\% bovine serum albumin (BSA; Roche Diagnostics, Minneapolis, MN, USA). Cells were then incubated with the EphA3 antibody (cat. no. sc-514209; Santa Cruz Biotechnology, Inc.) at a dilution of 1:50 for $1 \mathrm{~h}$ at $4^{\circ} \mathrm{C}$, washed with PBS and incubated with Alexa Fluor ${ }^{\circledR}$ 488-labeled secondary antibody (cat. no. ab150113; Abcam) at a dilution of 1:200 for $1 \mathrm{~h}$ at $4^{\circ} \mathrm{C}$. For actin staining, permeabilized cells were stained with rhodamine-labeled phalloidin $(0.1 \mu \mathrm{g} / \mathrm{ml}$; Cytoskeleton, Inc., Denver, CO, USA) for $1 \mathrm{~h}$ at room temperature. Stained cells were viewed under a fluorescence microscope (Olympus IX71; Olympus Corporation).

Migration and invasion assays. Cell migration and invasion assays were performed using Transwell chambers (pore size, $8 \mu \mathrm{m}$; Corning Incorporated, Corning, NY, USA) with or without a thin coating of Matrigel (Sigma-Aldrich; Merck KGaA). Briefly, $1 \times 10^{5}$ cells were seeded into the upper chamber of the plate in serum-free medium. Medium containing $10 \%$ FBS was used as chemoattractant in the lower chamber. After 28 and $50 \mathrm{~h}$, respectively, migration and invasion were evaluated by measuring the number of cells that had moved into the lower chambers. Cells that remained on 
the upper chamber were removed using a cotton swab, after which, the membranes were fixed in ice-cold methanol for $1 \mathrm{~h}$ at $4^{\circ} \mathrm{C}$ and stained with $0.5 \%$ crystal violet for $30 \mathrm{~min}$ at room temperature. Migrated/invasive cells on the underside of the filter were counted in five random fields at x200 magnification using an Olympus IX71 microscope (Olympus Corporation), and the mean number of cells was calculated. The experiments were performed in triplicate.

Protein extraction and western blotting. Cells were lysed with ice-cold radioimmunoprecipitation assay buffer $(50 \mathrm{mM}$ Tris, $\mathrm{pH} 7.4 ; 150 \mathrm{mM} \mathrm{NaCl} ; 1 \%$ sodium deoxycholate; $1 \%$ sodium dodecyl sulfate; $1 \%$ NP-40) supplemented with protease inhibitor cocktail (Roche Diagnostics). Cell lysates were incubated on ice for $0.5 \mathrm{~h}$ and insoluble proteins were removed by centrifugation at $10,000 \mathrm{x}$ g for $10 \mathrm{~min}$ at $4^{\circ} \mathrm{C}$. Protein concentrations were determined using the Bicinchoninic Acid Protein Assay kit (Beyotime Institute of Biotechnology, Haimen, China). Protein samples (20-50 $\mu \mathrm{g})$ were separated by SDS-PAGE (5\% stacking and 10\% separating gels) and were transferred onto polyvinylidene difluoride membranes (EMD Millipore, Billerica, MA, USA). The membranes were then blocked for $1 \mathrm{~h}$ at room temperature using $5 \% \mathrm{BSA}$, and the proteins were detected with specific primary antibodies and peroxidase-conjugated secondary antibodies at the dilutions recommended by the manufacturers, according to the protocols (Cell Signaling Technology, Inc.). Blots were visualized using the Chemiluminescent Substrate kit (Thermo Fisher Scientific, Inc.) and the Gel Doc ${ }^{\mathrm{TM}}$ XR system (Bio-Rad Laboratories, Inc., Hercules, CA, USA).

Detection of GTP-bound RhoA. The RhoA-binding domain (RBD) of the rhotekin protein was amplified by PCR from the MDA-MB-231 cell line cDNA bank (contained in our laboratory at the International Joint Cancer Institute, Second Military Medical University), cloned into the pGEX-4T-2 expression vector (Amersham; GE Healthcare, Chicago, IL, USA), and was expressed as a glutathione S-transferase (GST) fusion protein in BL21 (DE3) cells (International Joint Cancer Institute, Second Military Medical University). The levels of GTP-bound RhoA (active RhoA) in cell lysates were measured using immunoprecipitation, as previously described (23). Briefly, control and EphA3-overexpressing KYSE510 cells were lysed in M-PER Mammalian Protein Extraction Reagent (Thermo Fisher Scientific, Inc.) containing protease inhibitor cocktail (Roche Diagnostics) and were precleared with glutathione beads. The GST-RBD protein was allowed to bind to the glutathione bead at $4^{\circ} \mathrm{C}$ overnight and the supernatants of the precleared protein lysates were applied to these beads, allowing the active form of RhoA to bind to the RBD domain. Total RhoA levels in the cell lysate were compared to the pulled-down active RhoA by western blotting and were measured using Bio-Rad Quantity One 4.52 software (Bio-Rad Laboratories, Inc.).

$R N A$ extraction and reverse transcription-quantitative $P C R$ $(R T-q P C R)$. Total RNA was isolated from cultured cells or clinical samples using TRIzol ${ }^{\circledR}$ reagent (Invitrogen; Thermo Fisher Scientific, Inc.), according to the manufacturer's protocol.RT-qPCR was performed as described previously (24).
Briefly, cDNA was prepared from $1 \mu \mathrm{g}$ total RNA using AMV reverse transcriptase (Promega Corporation, Madison, WI, USA) and random primers (Promega Corporation), according to the manufacturer's protocol. For each gene, PCR reactions were run three times on each sample. PCR was performed using the Chromo4 Multicolor Real-Time Detection system (Bio-Rad Laboratories, Inc.) in 20- $\mu$ l reactions using SYBR $^{\mathrm{TM}}$-Green PCR Master Mix (Takara Bio, Inc., Otsu, Japan). The PCR thermal cycling conditions were as follows: Predenaturation at $95^{\circ} \mathrm{C}$ for $30 \mathrm{sec}$, followed by 40 cycles at $95^{\circ} \mathrm{C}$ for $10 \mathrm{sec}$ and $60^{\circ} \mathrm{C}$ for $40 \mathrm{sec}$, and a final extension step at $72^{\circ} \mathrm{C}$ for $5 \mathrm{~min}$. The relative mRNA expression levels were normalized to the endogenous control $\beta$-actin. Relative expression values were calculated using the $2^{-\Delta \Delta \mathrm{Cq}}$ method (25). Because SYBR-Green binding is not sequence specific, careful design and validation of each primer pair, as well as cautious manipulation of RNA were undertaken to ensure that only target gene sequence-specific, non-genomic products were amplified by qPCR. To achieve this, primers were designed to either span or flank introns. A dissociation curve analysis was performed at the end of amplification, in order to verify specificity of the PCR products. The same PCR products were also evaluated by agarose gel electrophoresis. Data are presented as the means \pm standard deviation of three independent experiments. The primers used are as follows: EphA3, forward 5'-ATTTTGGCAATGGGCATTTA-3', reverse 5'-ATGTATGTGGGTCAACATAAGTCC-3'; ZO-1, forward 5'-GGTCAGAGCCTTCTGATCATTC-3', reverse 5'-CATCTCTACTCCGGAGACTGC-3'; E-cadherin, forward 5'-AGGGGTCTGTCATGGAAGGT-3', reverse 5'-GCGGCA TTGTAGGTGTTCA-3'; Vimentin, forward 5'-TGGTCTAAC GGTTTCCCCTA-3', reverse 5'-GACCTCGGAGCGAGA GTG-3'; N-cadherin, forward 5'-GGTGGAGGAGAAGAA GACCAG-3', reverse 5'-GGCATCAGGCTCCACAGT-3'; Snail, forward 5'-TGGTTGCTTCAAGGACACAT-3', reverse 5'-GCAAATGCTCTGTTGCAGTG-3'; and $\beta$-actin, forward 5'-CCCGCGAGTACAACCTTCT-3' and reverse 5'-CGTCAT CCATGGCGAACT-3'.

RT-PCR. RT-PCR (Takara PCR Amplification kit, cat. no. R011; Takara Bio, Inc.) was performed on cDNA using EphA3-specific primers (forward, 5'-ATGTTTCCAGAC ACGGTACC-3' and reverse, 5'-CCATCTTCCTGAGTAGAA CTGTGAGG-3'), which yielded a 269 bp product. To serve as an internal control, a 335-bp fragment of $\beta$-actin cDNA was co-amplified using primers (forward, 5'-TTCCTGGGCATG GAGTCCTGTGG-3' and reverse 5'-CGCCTAGAAGCATTT GCGGTGG-3'). PCR was conducted as follows: Predenaturation at $94^{\circ} \mathrm{C}$ for $3 \mathrm{~min}$, followed by 25-30 cycles at $94^{\circ} \mathrm{C}$ for $1 \mathrm{~min}, 55^{\circ} \mathrm{C}$ for $0.5 \mathrm{~min}$ and $72^{\circ} \mathrm{C}$ for $0.5 \mathrm{~min}$, and followed a final extension step at $72^{\circ} \mathrm{C}$ for $5 \mathrm{~min}$. All PCR experiments were repeated at least twice and the products were separated by $1.5 \%$ agarose gel electrophoresis and were stained with ethidium bromide (cat. no. 160539; Sigma-Aldrich; Merck KGaA).

Statistical analysis. Statistical analyses were performed using Microsoft Excel Version 2007 (Microsoft Corporation, Redmond, WA, USA). Data are presented as the means \pm standard deviation. Differences between two groups 

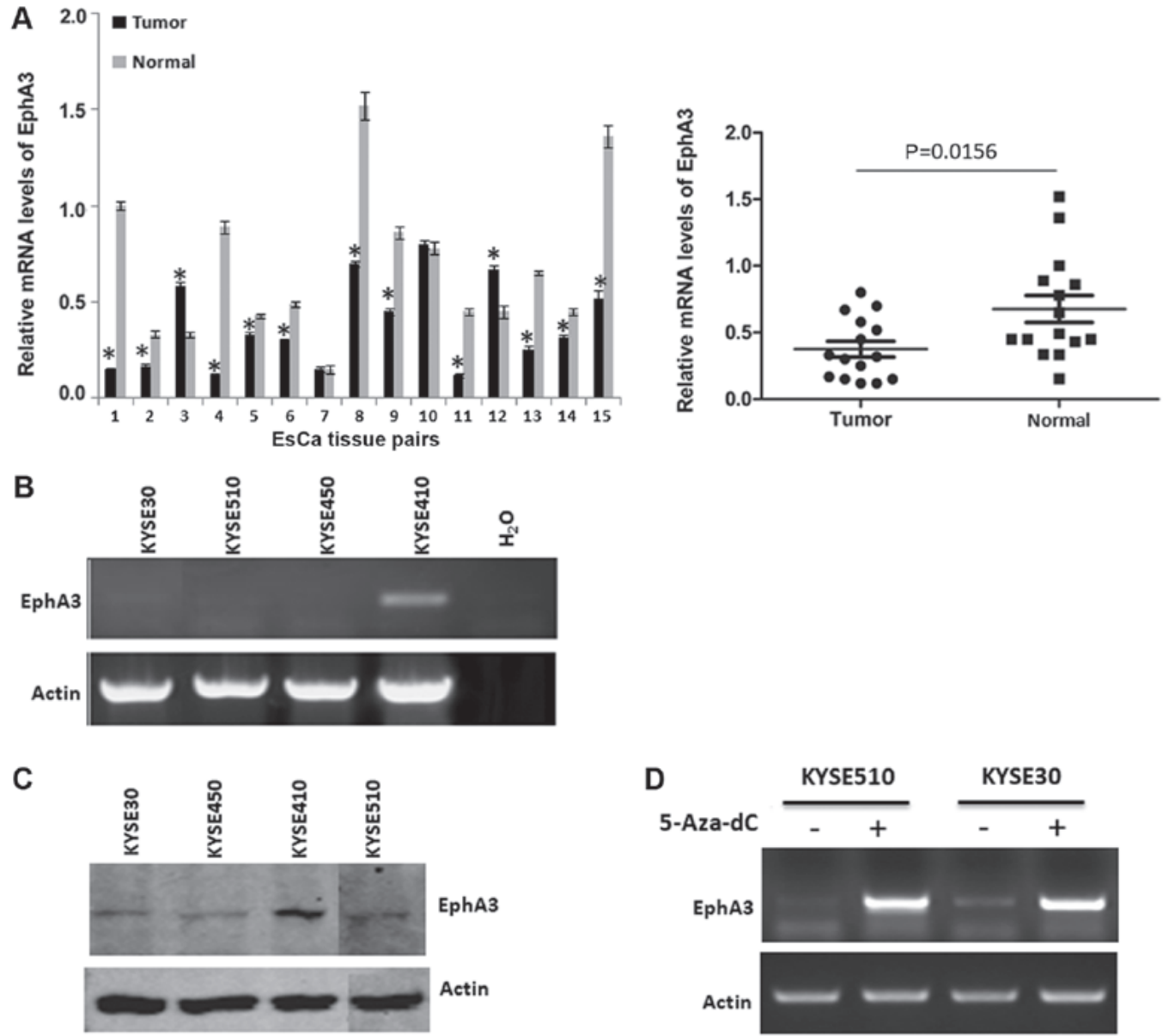

Figure 1. Expression levels of EphA3 are downregulated in esophageal cancer. The expression levels of EphA3 were detected in tissues and cell lines. (A) EphA3 mRNA expression levels were detected in esophageal cancer tissues and normal counterparts. (B) EphA3 mRNA expression levels were detected in esophageal cancer cell lines. (C) Western blotting of EphA3 protein expression in esophageal cancer cell lines. (D) EphA3 mRNA expression was observed in esophageal cancer cell lines (KYSE510 and KYSE30) treated with or without 5-Aza-dC. "P<0.05 vs. non-cancerous tissues. 5-Aza-dC, 5-aza-2'-deoxycytidine; EphA3, Eph receptor A3.

were compared using the Student's t-test. Differences between more than two groups were compared using one-way analysis of variance, followed by post hoc pairwise comparisons with the application of Dunn's test. $\mathrm{P}<0.05$ was considered to indicate a statistically significant difference.

\section{Results}

Expression levels of EphA3 in ESCC. To investigate EphA3 expression in ESCC, we assessed mRNA expression levels in clinical cancer specimens, and in a series of ESCC cell lines (Fig. 1). In the collected ESCC tissues, 11 out of 15 cancerous tissues expressed lower levels of EphA3 than their normal counterparts; further statistical analysis revealed that ESCC tissues were significantly decreased compared with in adjacent normal tissues (Fig. 1A). There was minimal or undetectable expression of EphA3 in three of the four cancerous cell lines (Fig. 1B and C). However, treatment with the DNA methylation inhibitor 5-Aza-dC increased the mRNA expression levels of EphA3 in the KYSE510 and KYSE30 cell lines (Fig. 1D). in the majority of ESCC tissues compared with in adjacent normal tissues, the present study aimed to investigate the role of EphA3 in ESCC. For this purpose, KYSE450 and KYSE510 ESCC cells were infected with an EphA3-expressing lentiviral vector or a control vector. Notably, KYSE450 and KYSE510 cells express low endogenous levels of EphA3. Infected cells were cultured for $24 \mathrm{~h}$, after which, cell that stably expressed EphA2 were selected using puromycin. These cell lines were used to determine whether EphA3 could affect migration and invasion of ESCC cells (Fig. 2).

To determine the effects of EphA3 on migration and invasion of KYSE450 and KYSE510 cells, in vitro assays were performed using a Transwell chamber. Overexpression of EphA3 significantly inhibited the migration of KYSE450 and KYSE510 cells in Transwell chambers (Fig. 2A and D). Furthermore, as determined following the addition of a thin layer of Matrigel onto the Transwell chamber membranes, EphA3 overexpression significantly inhibited the invasion of KYSE450 and KYSE510 cells (Fig. 2B and E). These data indicated that overexpression of EphA3 may suppress the migration and invasion of KYSE450 and KYSE510 cells.

EphA3 overexpression induces MET of KYSE450 and KYSE510 cells. Cells overexpressing EphA3 were analyzed to 

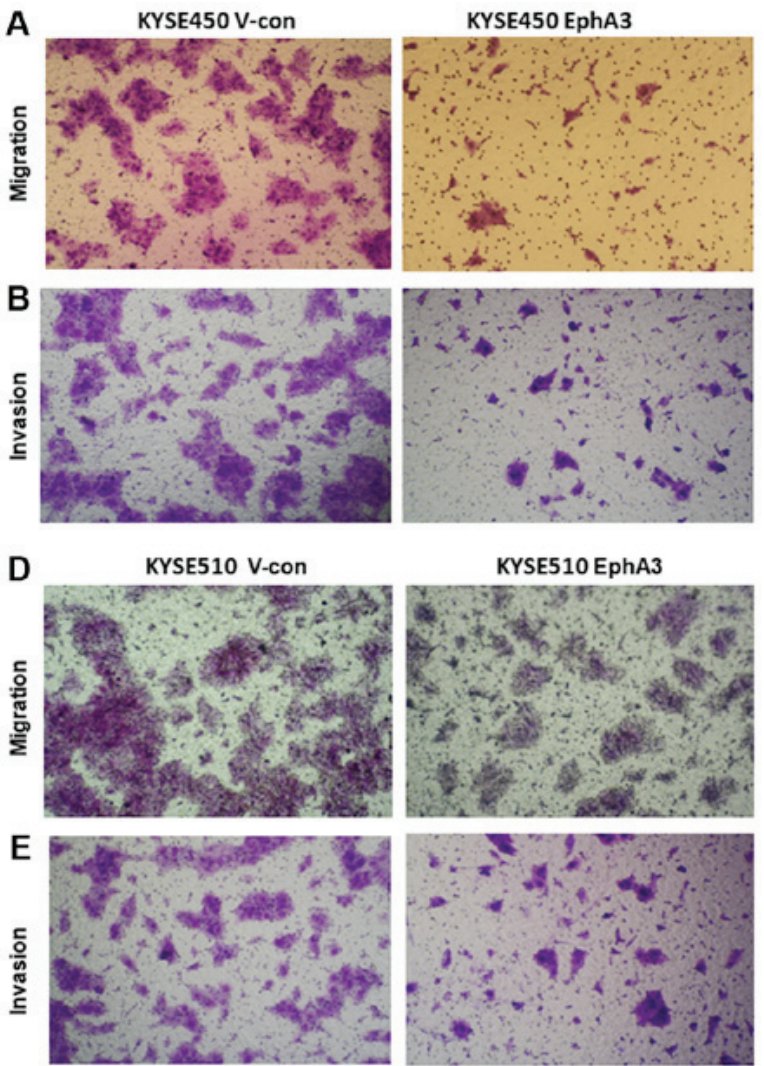

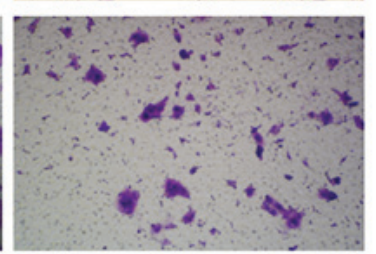

KYSE510 EphA3
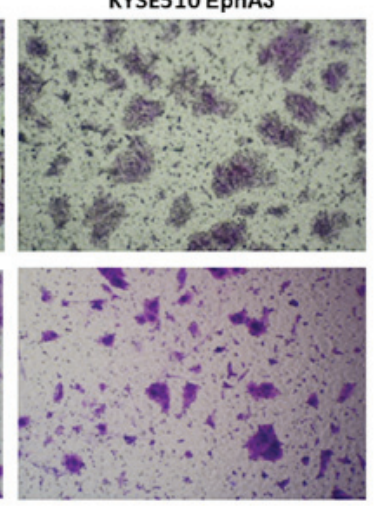
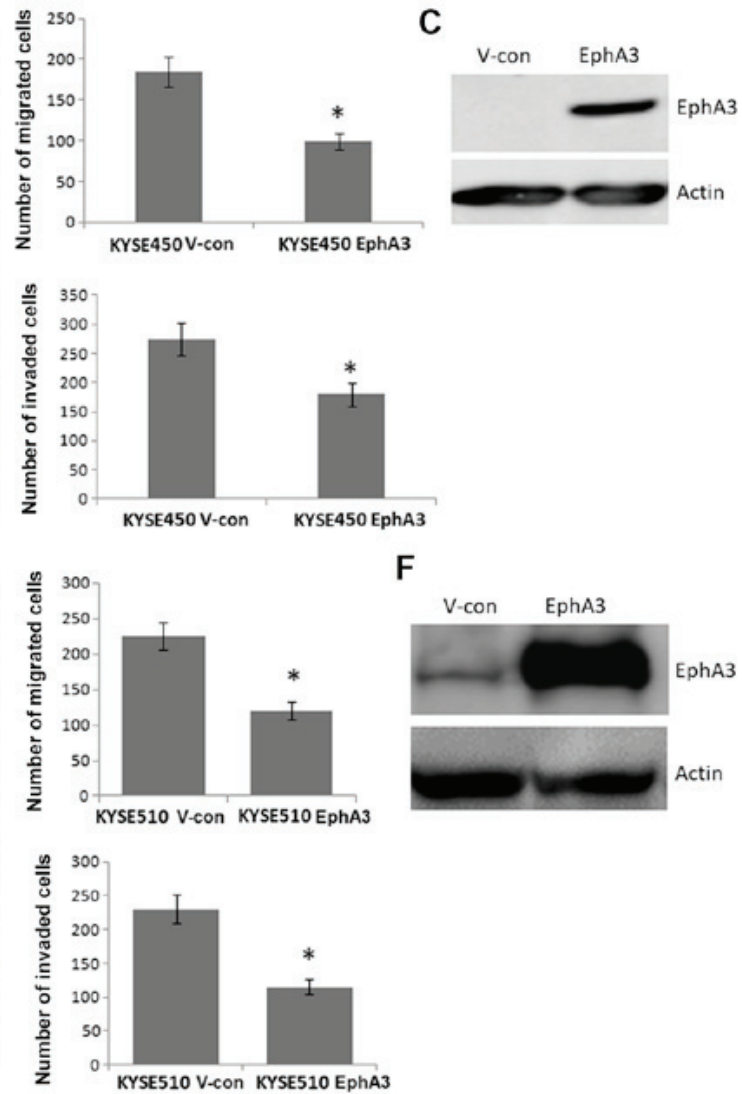

Figure 2. Overexpression of EphA3 inhibits the migration and invasion of KYSE450 and KYSE510 cells. (A and D) Cell migration was determined using Transwell chambers. EphA3 overexpression significantly inhibited cell migration. (B and E) Following the addition of a thin layer of Matrigel on the Transwell chamber membrane, cell invasion was determined in cells overexpressing EphA3 and control cells. Invasion was significantly inhibited in EphA3 overexpressing cells. Magnification, x200. (C and F) Western blot analysis of EphA3 protein expression in KYSE450 or KYSE510 cell lines post-transduction with an EphA3 overexpression vector. Data are presented as the means \pm standard deviation from three separate experiments. "P<0.05 vs. the V-con group. EphA3, Eph receptor A3; V-con, vector control.

determine the effects of EphA3 on EMT and MET (Fig. 3). Notably, morphological alterations characteristic of MET were observed in KYSE450 and KYSE510 ESCC cells stably expressing EphA3. As shown in Fig. 3A and D, while the control cells appeared elongated, which is a characteristic of mesenchymal cells, cells overexpressing EphA3 exhibited the more rounded shape characteristic of epithelial cells. The morphological observations and Transwell assay results resulted in the hypothesis that EphA3 overexpression may affect the EMT process of ESCC during tumor metastasis. In addition, the expression levels of EMT-associated genes were detected by RT-qPCR. As shown in Fig. 3B and E, the mRNA expression levels of the epithelial cell markers E-cadherin and ZO-1 were upregulated, whereas the mesenchymal cell markers Vimentin and $\mathrm{N}$-cadherin were downregulated compared with in the control cells. Furthermore, the mRNA expression levels of Snail, which is an E-cadherin-suppressing gene, were also downregulated (Fig. 3B and E). Concordantly, western blotting confirmed the upregulated expression of E-cadherin and ZO-1, and downregulated expression of Vimentin compared with in the vector control cells (Fig. 3C and F). These data suggested that EphA3 overexpression may induce the MET process in KYSE450 and KYSE510 cells.

EphA3 function depends on its kinase activity and tyrosine phosphorylation status. To examine the molecular mechanisms underlying the effects of EphA3 overexpression on cell morphology and behavior, the present study addressed the dependence of these cellular effects on EphA3 kinase activity and tyrosine phosphorylation status within the EphA3 cytoplasmic domain. Briefly, the effects of the kinase-null mutant K653R (a mutant containing a lysine to arginine mutation at amino acid position 653 , which is known to inactivate EphA3 kinase activity) $(26,27)$ and the phenylalanine replacement mutants of conserved tyrosine residues (Y596, Y602, Y779) were determined. These tyrosine residues are believed to function together to regulate the kinase activity of EphA3 $(27,28)$. Wild type and mutant receptors were expressed at comparable levels in transduced cells (Fig. 4A).

Transduction of cells with EphA3 harboring mutations in all three tyrosines (3YF) or a kinase-null mutation (K653R) did not induce drastic MET-like alterations (Fig. 4B). Cell migration and invasion assays revealed that these mutations alleviated the inhibitory effects of EphA3 (Fig. 4C and D). These observations suggested that the functions of EphA3 were dependent on its kinase activity and tyrosine phosphorylation status in vitro.

Silencing EphA3 induces EMT, and promotes migration and invasion of KYSE 410 cells. Three shRNA sequences corresponding to the EphA3 gene, and one control shRNA sequence, were designed and inserted into a lentiviral vector, 
A

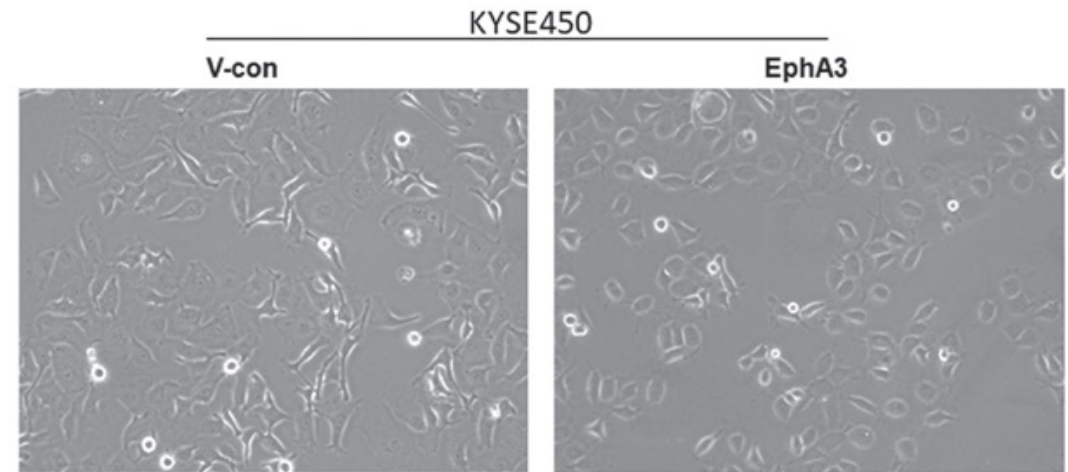

B

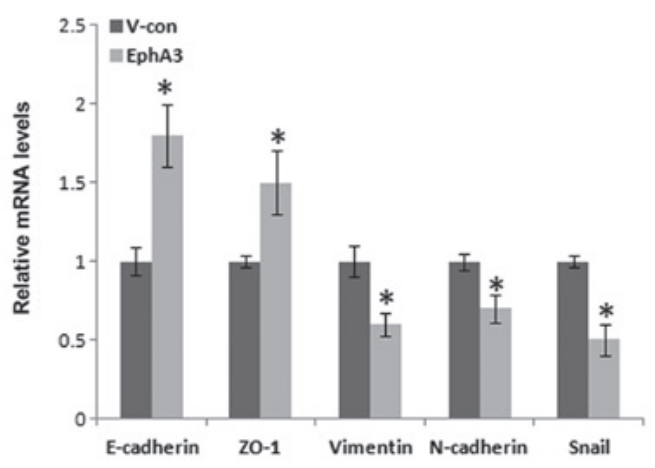

C

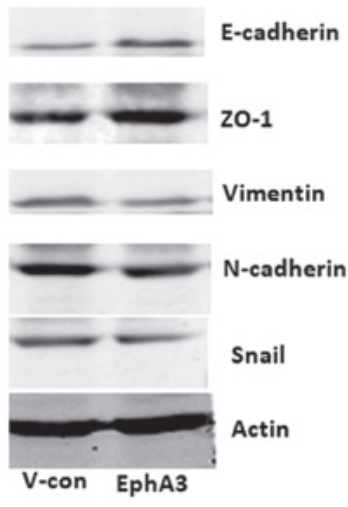

D KYSE510

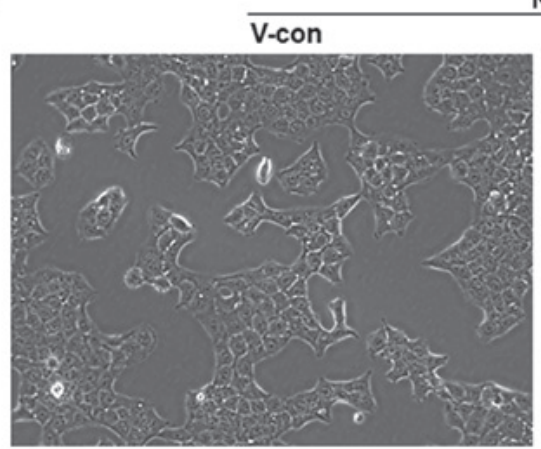

E

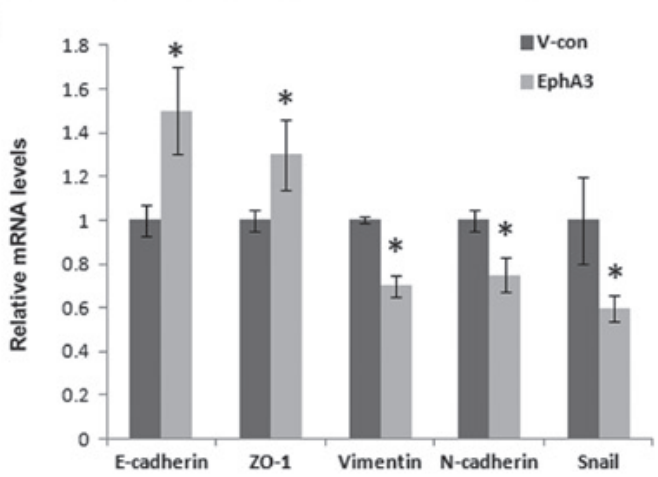

$\mathbf{F}$

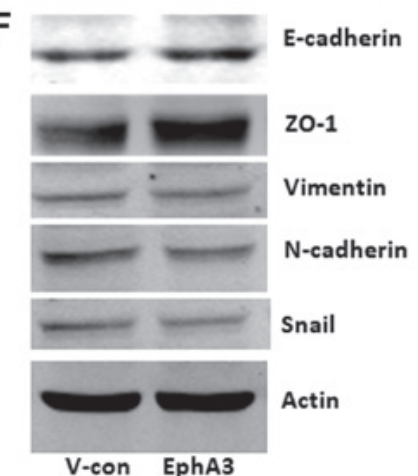

Figure 3. EphA3 overexpression induces the MET process in KYSE450 and KYSE510 cells. (A and D) Morphlogical alterations in cells following EphA3 overexpression; notably, cell borders appeared smoother and rounder. Magnification, x200. (B and E) Results of quantitative polymerase chain reaction indicated that epithelial marker genes (E-cadherin and ZO-1) were upregulated and mesenchymal marker genes (Vimentin and N-cadherin) were downregulated in cells overexpressing EphA3. The mRNA expression levels of Snail were also downregulated. Gene expression was normalized to the housekeeping gene $\beta$-actin. (C and F) Western blotting indicated that E-cadherin and ZO-1 were increased, whereas Vimentin, N-cadherin and Snail were decreased in cells overexpressing EphA3 compared with in the V-con cells. Data are presented as the means \pm standard deviation from three separate experiments. ${ }^{*}<0.05$ vs. the V-con group. EphA3, Eph receptor A3; V-con, vector control; ZO-1, zonula occludens-1.

which was infected into KYSE410 cells, in order to generate a EphA3 knockdown cell line. KYSE410 cells express high endogenous levels of EphA3. As shown in Fig. 5, knockdown of EphA3 induced EMT morphological alterations, and promoted cell migration and invasion. Furthermore, the mRNA expression levels of the epithelial cell markers E-cadherin and ZO-1 were downregulated, whereas the mesenchymal cell markers Vimentin and $\mathrm{N}$-cadherin were 
A

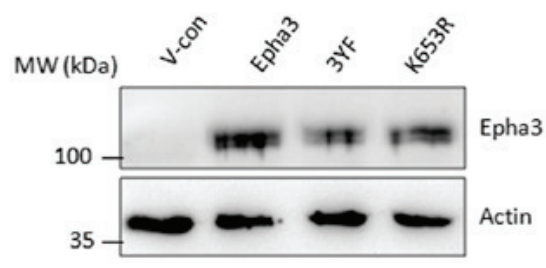

B

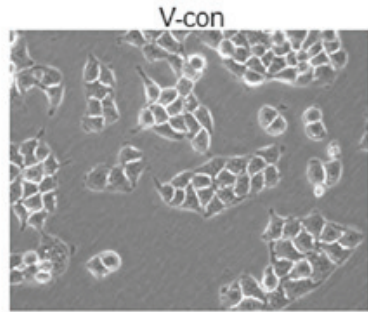

$3 Y F$

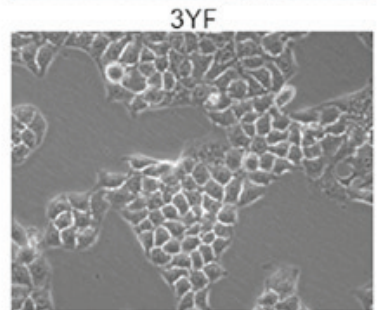

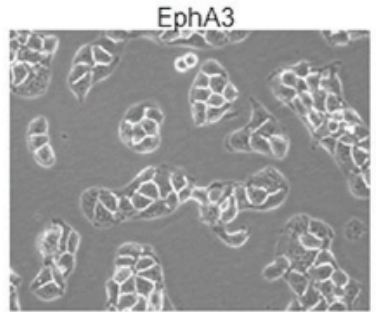

K653R

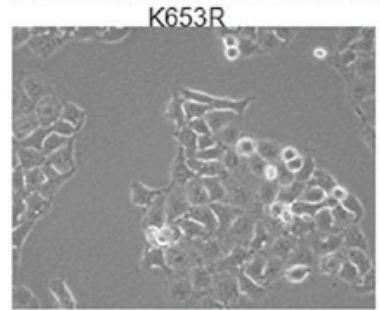

\section{C}
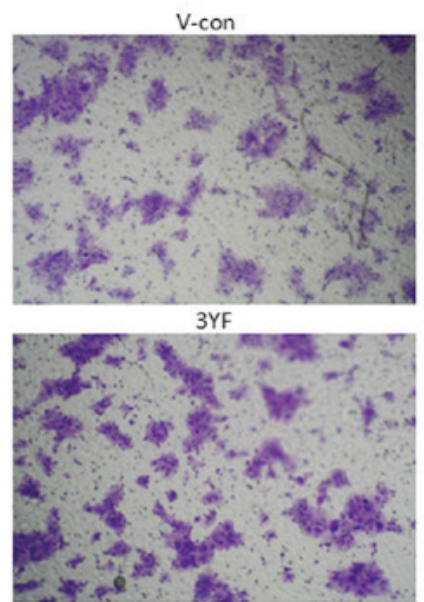

D

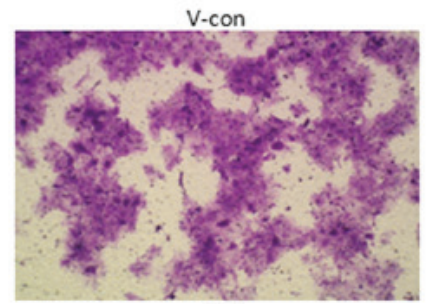

3YF
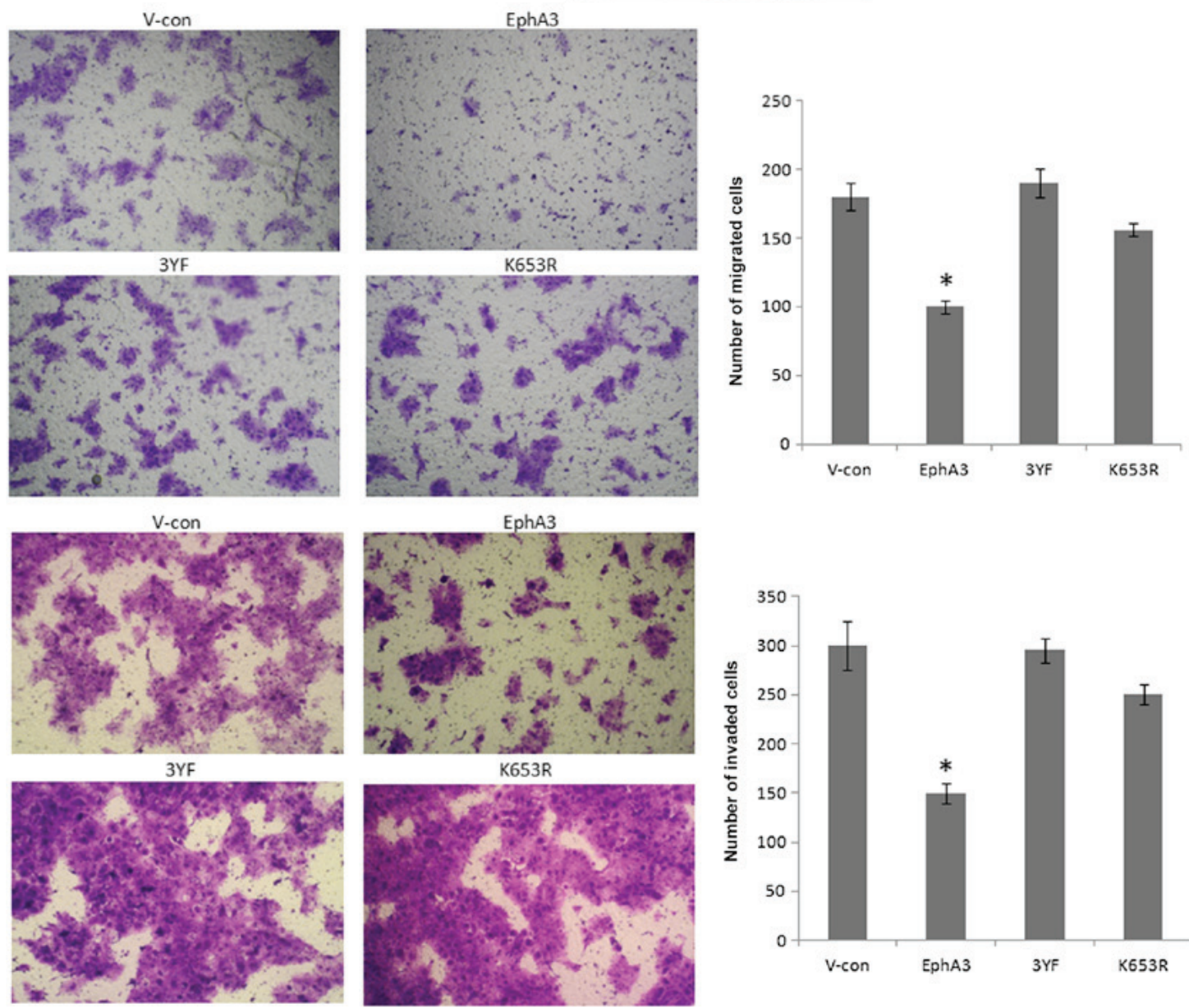

K653R
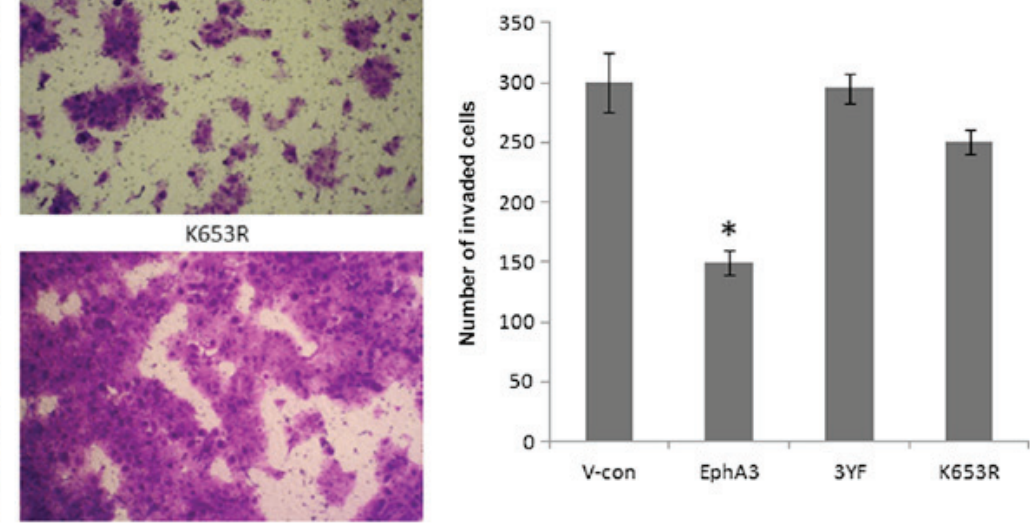

Figure 4. Effects of mutant EphA3 on cell morphology and cellular behavior. (A) EphA3 protein expression was detected in KYSE510 cells transduced with wild type and mutant EphA3. (B) EphA3 overexpression induced morphological alterations characteristic of mesenchymal-epithelial transition, whereas transduction with 3 YF and K653R mutants weakened this effect. Magnification, x200. EphA3 overexpression prevented cell (C) migration and (D) invasion, whereas the mutants attenuated its effects. Data are presented as the means \pm standard deviation from three separate experiments. $\mathrm{P}<0.05 \mathrm{vs}$. the $\mathrm{V}$-con group. EphA3, Eph receptor A3; V-con, vector control.

upregulated compared with in the control cells (Fig. 5C). Furthermore, the mRNA expression levels of Snail were also upregulated. These data suggested that silencing EphA3 may induce EMT, and promote migration and invasion of KYSE410 cells.

EphA3 functions are mediated by reducing RhoA activity. Small Rho GTPase signaling has been reported to contribute to invasion and metastasis, and participates in regulating EMT, MET and cytoskeletal signaling events $(29,30)$. Their activities are modulated by cycling between a GDP-bound inactive form and a GTP-bound active form. To analyze the possible signal transduction machinery in ESCC underlying EphA3-mediated inhibition of migration and EMT, the present study focused on the Rho signaling pathway. The activated RhoA levels were detected in cell lysates using a GST pull-down assay, by virtue 
A

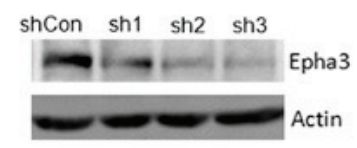

B

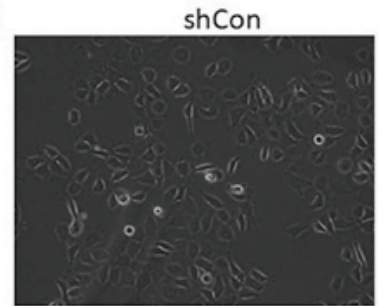

$\operatorname{sh} 2$

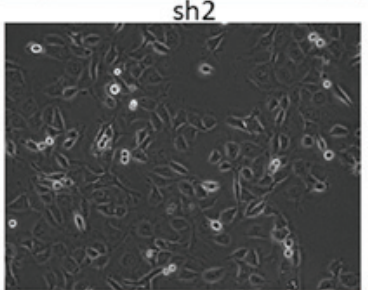

$\operatorname{sh} 1$
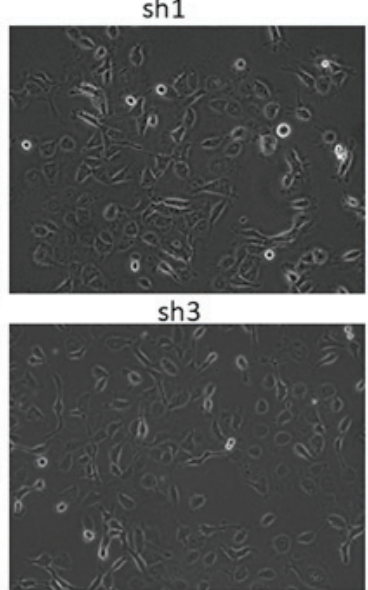

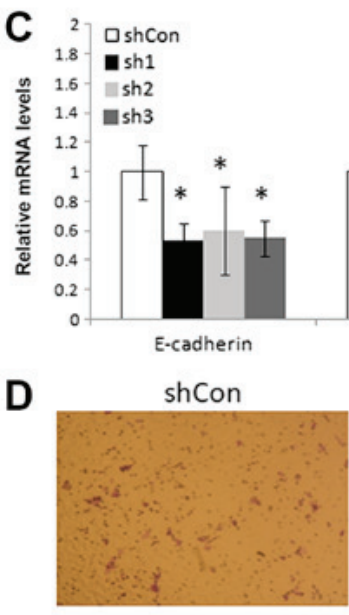

$\operatorname{sh} 2$

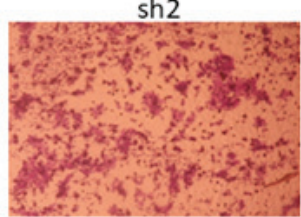

E

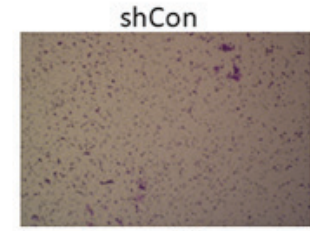

$\operatorname{sh} 2$

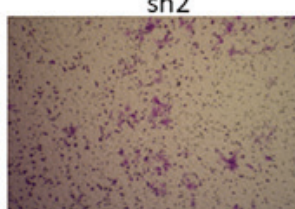

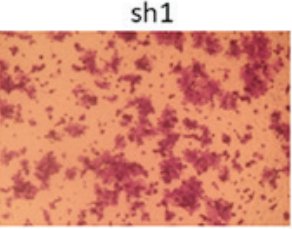

$\operatorname{sh} 3$

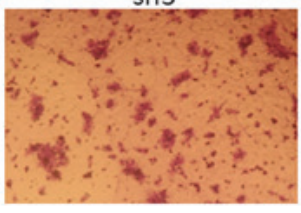

$\operatorname{sh} 1$

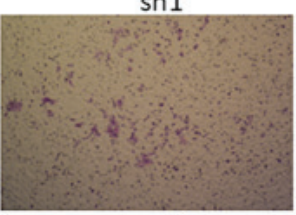

sh3

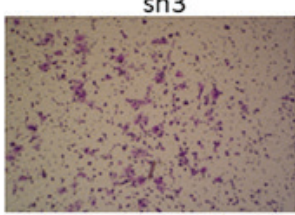

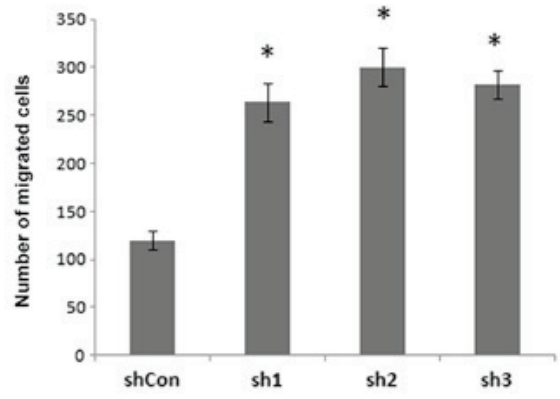

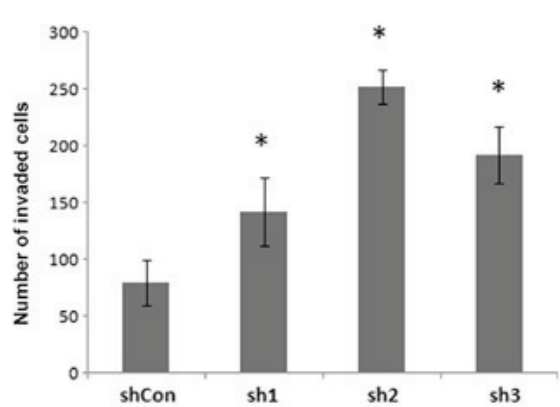

Figure 5. Silencing EphA3 induces EMT, and promotes migration and invasion of KYSE410 cells. (A) shRNA-mediated knockdown of EphA3 in the KYSE410 cell line. (B) Morphological alterations mediated by knockdown of EphA3 in KYSE410 cells. EphA3 knockdown induced EMT-like morphological alterations; cells became slender and had more protrusions. Magnification, x200. (C) Reverse transcription-quantitative polymerase chain reaction results indicated downregulation of epithelial marker genes (E-cadherin and ZO-1) and upregulation of mesenchymal marker genes (Vimentin and N-cadherin). The mRNA expression levels of Snail were also upregulated. (D) Silencing EphA3 in KYSE410 cells promoted cell migration, as determined by Transwell assay. (E) Silencing EphA3 in KYSE410 cells promoted cell invasion. Magnification, x200. Data are presented as the means \pm standard deviation from three separate experiments. "P<0.05 vs. shCon EMT, epithelial-mesenchymal transition; EphA3, Eph receptor A3; sh/shRNA, short hairpin RNA; shCon, control shRNA; ZO-1, zonula occludens-1.

of its binding ability to the RBD of rhotekin protein, according to Wahl et al (31).

The RBD-bound, active RhoA-GTP level was reduced in EphA3-overexpressing cells compared with the control cells (Fig. 6A). Furthermore, staining of permeabilized cells with rhodamine-phalloidin revealed that the actin cytoskeleton network was largely reorganized and intracellular stress fiber formation was reduced in EphA3-overexpressing cells. There 

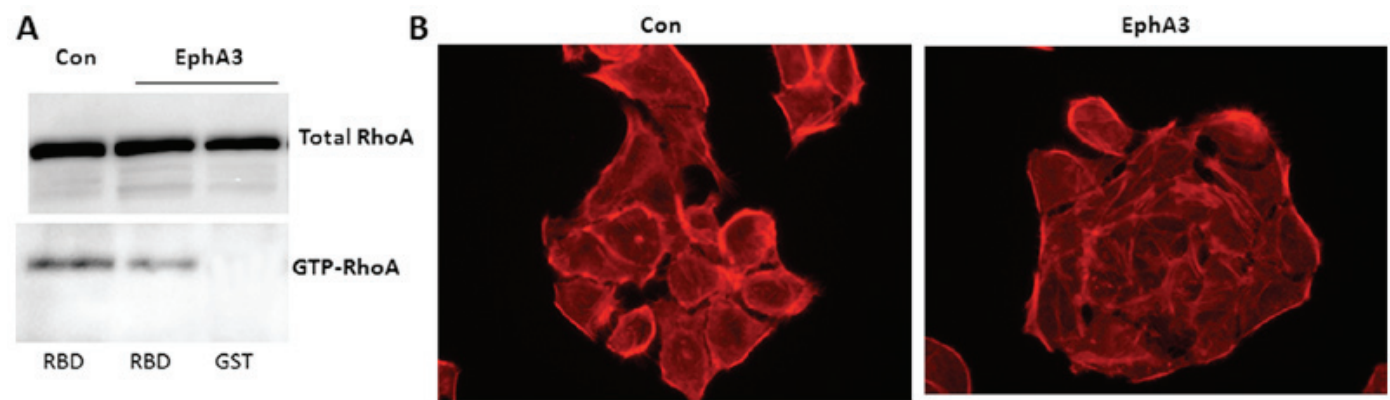

Figure 6. EphA3 function in ESCC cells is mediated by reducing RhoA activity. (A) GST pull-down and western blotting were used to determine active RhoA. (B) Intracellular actin distribution in EphA3-overexpressing cells, as determined by rhodamine-phalloidin staining. Magnification, x400. EphA3, Eph receptor A3; GST, glutathione S-transferase; RBD, RhoA-binding domain; con, control.

were more complex actin networks with distinct fiber bundles extending into cell protrusions and lamellipodia in the control cells (Fig. 6B).

\section{Discussion}

The Eph receptors and their ligands, ephrins, mediate important processes in embryonic development, particularly in tissue organization, by modulating cell adhesion or repulsion. Altered expression of Eph receptors and ephrins is associated with angiogenesis and tumor vasculature in numerous types of human cancer, including breast, lung and prostate cancer, melanoma and leukaemia $(8,32-34)$. Alterations in their expression profiles in several types of cancer have resulted in this protein family being considered prime targets for cancer prognosis and therapy (35-38). EphA3 (formerly known as HEK) is presently one of the most promising therapeutic targets $(39,40)$. EphA3 expression is associated with tumor promotion in various cancer types, whereas it serves a tumor-suppressor role in others (40). EphA3 gene copy numbers and/or expression levels have been reported to be decreased in lung cancer, and re-expression of wild-type EphA3 in cell lines increases apoptosis by suppressing activity of prosurvival protein kinase $\mathrm{B}$, and inhibits the growth of tumor xenografts (41).

The present study revealed that EphA3 expression was decreased in ESCC tissues and cell lines compared with in the normal counterparts. These findings were concordant with those of previous studies, which revealed that the EphA3 gene is deleted in ESCC (20,21). In addition, treatment with 5-Aza-dC increased the mRNA expression levels of EphA3 in KYSE510 and KYSE30 cells, thus suggesting that inhibition of DNA methyltransferase can enhance EphA3 expression. Silencing of EphA3 expression by DNA hypermethylation also occurs in leukemia (14). In addition, irradiation of metastatic human melanoma cells leads to decreased cell migration alongside downregulation of EphA2 and upregulation of EphA3 (42). In this study, overexpression of EphA3 inhibited the migration and invasion of KYSE450 and KYSE510 cells. Furthermore, shRNA-mediated knockdown of EphA3 in KYSE410 cells promoted cell migration and invasion, thus suggesting that it may act as a tumor suppressor in ESCC. Future studies are required to test and verify the tumor-suppressor role of EphA3 in ESCC using an animal model of metastasis.

The EMT process is an important event in the tumor invasion-metastasis cascade (43), during which epithelial cells lose their sheet-like architecture, cell polarity and cell to cell adhesion, and then undergo marked cytoskeletal remodeling, and gain migratory and invasive properties to become mesenchymal stem cells. These effects are largely mediated through the recruitment of signaling molecules associated with cytoskeletal organization and integrin signaling (44). During actin cytoskeletal reorganization, important dynamic structures, such as membrane protrusions (including lamellipodia, membrane ruffles, lamellae and filopodia) and stress fibers are formed. It has been reported that this process is mediated by the actions of the three best-characterized small GTPases, including Rho, Rac and cell division control protein 42. Furthermore, it has been indicated that the RhoA/ROCK-dependent pathway participates in regulating EMT, MET and cytoskeletal signaling events, and is crucial for cell motility. EphA3-knockout mice have been reported to have a heart valve defect, which is thought to result from defective EMT, with fewer migrating mesenchymal cells (12). Conversely, EphA3 overexpression promotes EMT in chick atrioventricular cushion explants (45). However, the present study observed MET-like morphological alterations in EphA3-overexpressing ESCC cells, as determined using phase-contrast micrographs. In addition, overexpression of EphA3 upregulated epithelial proteins (E-cadherin and ZO-1) and downregulated mesenchymal proteins (Vimentin, N-cadherin and Snail). Furthermore, stress fiber formation was reduced in EphA3-overexpressing cells, as determined by phalloidin staining. EphA3 overexpression also decreased RhoA GTPase, thus suggesting that EphA3 may suppress ESCC cancer migration and invasion, at least partially through small GTPase RhoA activation.

Together with the activation-loop tyrosine, two conserved tyrosines in the juxtamembrane region of Eph receptors function to regulate kinase activity, and their phosphorylation is crucial for full enzyme activity $(28,46)$. These juxtamembrane tyrosines are important for signal transfer, and have been suggested to act as docking sites for some known signaling molecules, including Fyn, Src, RasGAP and Nck $(47,48)$; the majority of these molecules are involved in organization of the cytoskeleton $(49,50)$, thus supporting an emerging concept that Eph receptors regulate cell adhesion and plasticity of the actin cytoskeleton (51). It is well known that the K653R mutant is a kinase-null mutant of EphA3 that results in inactivation of its kinase activity; in addition, phosphorylation of the conserved residue Y596 is critical to its kinase activity. Tyrosine phosphorylation of the other two conserved residues, Y602 and Y779, has also been reported to collaborate to execute the 
full cellular activity of EphA3 $(27,28,52)$. In the present study, cells infected with EphA3 harboring mutations in all three tyrosines (3YF) or a kinase-null mutation (K653R) did not exhibit marked MET-like alterations, and cell migration and invasion were not significantly inhibited. A limitation of the present study is that kinase activity assays were not conducted and the phosphorylation levels of these specific mutants were not detected. The results of the present study suggested that the functions of EphA3 were dependent on kinase activity and tyrosine phosphorylation status. In conclusion, this study indicated that EphA3 expression was significantly suppressed in ESCC due to promoter methylation, whereas its overexpression prevented cancer cells from undergoing EMT, and inhibited cell migration and invasion via the Rho GTPase signaling pathway.

\section{Acknowledgements}

Not applicable.

\section{Funding}

The present study was supported by grants from the National Natural Science Foundation of China (grant nos. 81101574 and 81570557).

\section{Availability of data and materials}

All data generated or analyzed during this study are included in this published article.

\section{Authors' contributions}

$\mathrm{XC}$ designed the study, carried out molecular cloning experiments and cellular experiments, and drafted the manuscript. QM performed the immunoblotting assays. BL and CDJ participated in study coordination, and helped to collect and analyze the data. JZL participated in the design of the study and drafted the manuscript. All authors read and approved the final manuscript.

\section{Ethics approval and consent to participate}

The present study was approved by the Ethics Committee of the Second Military Medical University. Written informed consent was obtained from each patient or from his/her legal guardians.

\section{Patient consent for publication}

All patients provided written informed consent.

\section{Competing interests}

The authors declare that they have no competing interests.

\section{References}

1. Liu Y,Xiong Z, Beasley A,D'Amico T and Chen XL: Personalized and targeted therapy of esophageal squamous cell carcinoma: An update. Ann N Y Acad Sci 1381: 66-73, 2016.
2. Ferlay J, Shin HR, Bray F, Forman D, Mathers C and Parkin DM: Estimates of worldwide burden of cancer in 2008: GLOBOCAN 2008. Int J Cancer 127: 2893-2917, 2010.

3. Baba Y, Watanabe M, Yoshida N and Baba H: Neoadjuvant treatment for esophageal squamous cell carcinoma. World J Gastrointest Oncol 6: 121-128, 2014.

4. Pennathur A, Gibson MK, Jobe BA and Luketich JD: Oesophageal carcinoma. Lancet 381: 400-412, 2013.

5. Pasquale EB: Eph receptors and ephrins in cancer: Bidirectional signalling and beyond. Nat Rev Cancer 10: 165-180, 2010.

6. Zelinski DP, Zantek ND, Stewart JC, Irizarry AR and Kinch MS: EphA2 overexpression causes tumorigenesis of mammary epithelial cells. Cancer Res 61: 2301-2306, 2001.

7. Easty DJ, Herlyn M and Bennett DC: Abnormal protein tyrosine kinase gene expression during melanoma progression and metastasis. Int J Cancer 60: 129-136, 1995.

8. Herath NI, Spanevello MD, Doecke JD, Smith FM, Pouponnot C and Boyd AW: Complex expression patterns of Eph receptor tyrosine kinases and their ephrin ligands in colorectal carcinogenesis. Eur J Cancer 48: 753-762, 2012.

9. Nieto MA, Huang RY, Jackson RA and Thiery JP: Emt: 2016. Cell 166: 21-45, 2016.

10. Wicks IP, Wilkinson D, Salvaris E and Boyd AW: Molecular cloning of HEK, the gene encoding a receptor tyrosine kinase expressed by human lymphoid tumor cell lines. Proc Natl Acad Sci USA 89: 1611-1615, 1992.

11. Gale NW, Holland SJ, Valenzuela DM, Flenniken A, Pan L, Ryan TE, Henkemeyer M, Strebhardt K, Hirai H, Wilkinson DG, et al: Eph receptors and ligands comprise two major specificity subclasses and are reciprocally compartmentalized during embryogenesis. Neuron 17: 9-19, 1996.

12. Stephen LJ, Fawkes AL, Verhoeve A, Lemke G and Brown A: A critical role for the EphA3 receptor tyrosine kinase in heart development. Dev Biol 302: 66-79, 2007.

13. Chiari R, Hames G, Stroobant V, Texier C, Maillère B, Boon T and Coulie PG: Identification of a tumor-specific shared antigen derived from an Eph receptor and presented to CD4 T cells on HLA class II molecules. Cancer Res 60: 4855-4863, 2000.

14. Dottori M, Down M, Hüttmann A, Fitzpatrick DR and Boyd AW: Cloning and characterization of EphA3 (Hek) gene promoter: DNA methylation regulates expression in hematopoietic tumor cells. Blood 94: 2477-2486, 1999.

15. Lawrenson ID, Wimmer-Kleikamp SH, Lock P, Schoenwaelder SM, Down M, Boyd AW, Alewood PF and Lackmann M: Ephrin-A5 induces rounding, blebbing and de-adhesion of EphA3-expressing 293T and melanoma cells by CrkII and Rho-mediated signalling. J Cell Sci 115: 1059-1072, 2002.

16. Xi HQ, Wu XS, Wei B and Chen L: Aberrant expression of EphA3 in gastric carcinoma: Correlation with tumor angiogenesis and survival. J Gastroenterol 47: 785-794, 2012.

17. Davies H, Hunter C, Smith R, Stephens P, Greenman C, Bignell G, Teague J, Butler A, Edkins S, Stevens C, et al: Somatic mutations of the protein kinase gene family in human lung cancer. Cancer Res 65: 7591-7595, 2005.

18. Stephens P, Edkins S, Davies H, Greenman C, Cox C, Hunter C, Bignell G, Teague J, Smith R, Stevens C, et al: A screen of the complete protein kinase gene family identifies diverse patterns of somatic mutations in human breast cancer. Nat Genet 37: 590-592, 2005

19. Wood LD, Calhoun ES, Silliman N, Ptak J, Szabo S, Powell SM, Riggins GJ, Wang TL, Yan H, Gazdar A, et al: Somatic mutations of GUCY2F, EPHA3, and NTRK3 in human cancers. Hum Mutat 27: 1060-1061, 2006.

20. Brown J, Bothma H, Veale R and Willem P: Genomic imbalances in esophageal carcinoma cell lines involve Wnt pathway genes. World J Gastroenterol 17: 2909-2923, 2011.

21. Chen J, Guo L, Peiffer DA, Zhou L, Chan OT, Bibikova M, Wickham-Garcia E, Lu SH, Zhan Q, Wang-Rodriguez J, et al: Genomic profiling of 766 cancer-related genes in archived esophageal normal and carcinoma tissues. Int J Cancer 122: 2249-2254, 2008.

22. Li JZ, Chen X, Gong XL, Hu HY, Shi D, Lu YM, Qiu L, Lu F, $\mathrm{Hu}$ ZL and Zhang JP: Identification of a functional nuclear localization signal mediating nuclear import of the zinc finger transcription factor ZNF24. PLoS One 8: e79910, 2013.

23. Ren XD, Kiosses WB and Schwartz MA: Regulation of the small GTP-binding protein Rho by cell adhesion and the cytoskeleton. EMBO J 18: 578-585, 1999. 
24. Li J, Chen X, Gong X, Liu Y, Feng H, Qiu L, Hu Z and Zhang J: A transcript profiling approach reveals the zinc finger transcription factor ZNF191 is a pleiotropic factor. BMC Genomics 10: 241, 2009.

25. Livak KJ and Schmittgen TD: Analysis of relative gene expression data using real-time quantitative PCR and the 2(-Delta Delta C(T)) method. Methods 25: 402-408, 2001.

26. BrennamanLH,MossMLandManessPF:EphrinA/EphA-induced ectodomain shedding of neural cell adhesion molecule regulates growth cone repulsion through ADAM10 metalloprotease. J Neurochem 128: 267-279, 2014.

27. Hu T, Shi G, Larose L, Rivera GM, Mayer BJ and Zhou R: Regulation of process retraction and cell migration by EphA3 is mediated by the adaptor protein Nck1. Biochemistry 48: 6369-6378, 2009.

28. Binns KL, Taylor PP, Sicheri F, Pawson T and Holland SJ: Phosphorylation of tyrosine residues in the kinase domain and juxtamembrane region regulates the biological and catalytic activities of Eph receptors. Mol Cell Biol 20: 4791-4805, 2000.

29. Etienne-Manneville S and Hall A: Rho GTPases in cell biology. Nature 420: 629-635, 2002

30. Sahai E and Marshall CJ: RHO-GTPases and cancer. Nat Rev Cancer 2: 133-142, 2002.

31. Wahl S, Barth H, Ciossek T, Aktories K and Mueller BK Ephrin-A5 induces collapse of growth cones by activating Rho and Rho kinase. J Cell Biol 149: 263-270, 2000.

32. Dodelet VC and Pasquale EB: Eph receptors and ephrin ligands: Embryogenesis to tumorigenesis. Oncogene 19: 5614-5619, 2000

33. Clevers $\mathrm{H}$ and Batlle $\mathrm{E}$ : EphB/Ephrin B receptors and Wnt signaling in colorectal cancer. Cancer Res 66: 2-5, 2006.

34. Surawska H, Ma PC and Salgia R: The role of ephrins and Eph receptors in cancer. Cytokine Growth Factor Rev 15: 419-433, 2004

35. Oricchio E, Nanjangud G, Wolfe AL, Schatz JH, Mavrakis KJ, Jiang M, Liu X, Bruno J, Heguy A, Olshen AB, et al: The Eph-receptor A7 is a soluble tumor suppressor for follicular lymphoma. Cell 147: 554-564, 2011.

36. Hatano M, Eguchi J, Tatsumi T, Kuwashima N, Dusak JE, Kinch MS, Pollack IF, Hamilton RL, Storkus WJ and Okada H: EphA2 as a glioma-associated antigen: A novel target for glioma vaccines. Neoplasia 7: 717-722, 2005

37. Lee JW, Han HD, Shahzad MM, Kim SW, Mangala LS, Nick AM, Lu C, Langley RR, Schmandt R, Kim HS, et al: EphA2 immunoconjugate as molecularly targeted chemotherapy for ovarian carcinoma. J Natl Cancer Inst 101: 1193-1205, 2009

38. Kiewlich D, Zhang J, Gross C, Xia W, Larsen B, Cobb RR, Biroc S, Gu JM, Sato T, Light DR, et al: Anti-EphA2 antibodies decrease EphA2 protein levels in murine CT26 colorectal and human MDA-231 breast tumors but do not inhibit tumor growth. Neoplasia 8: 18-30, 2006.
39. Boyd AW, Ward LD, Wicks IP, Simpson RJ, Salvaris E, Wilks A, Welch K, Loudovaris M, Rockman S and Busmanis I: Isolation and characterization of a novel receptor-type protein tyrosine kinase (hek) from a human pre-B cell line. J Biol Chem 267: 3262-3267, 1992.

40. Janes PW, Slape CI, Farnsworth RH, Atapattu L, Scott AM and Vail ME: EphA3 biology and cancer. Growth Factors 32: 176-189, 2014.

41. Zhuang G, Song W, Amato K, Hwang Y, Lee K, Boothby M, Ye F, Guo Y, Shyr Y, Lin L, et al: Effects of cancer-associated EPHA3 mutations on lung cancer. J Natl Cancer Inst 104: 1182-1197, 2012.

42. Mosch B, Pietzsch D and Pietzsch J: Irradiation affects cellular properties and Eph receptor expression in human melanoma cells. Cell Adhes Migr 6: 113-125, 2012.

43. Grant CM and Kyprianou N: Epithelial mesenchymal transition (EMT) in prostate growth and tumor progression. Transl Androl Urol 2: 202-211, 2013.

44. Miao H, Burnett E, Kinch M, Simon E and Wang B: Activation of EphA2 kinase suppresses integrin function and causes focal-adhesion-kinase dephosphorylation. Nat Cell Biol 2: 62-69, 2000.

45. Frieden LA, Townsend TA, Vaught DB, Delaughter DM, Hwang Y, Barnett JV and Chen J: Regulation of heart valve morphogenesis by Eph receptor ligand, ephrin-A1. Dev Dyn 239: 3226-3234, 2010

46. Zisch AH, Pazzagli C, Freeman AL, Schneller M, Hadman M, Smith JW, Ruoslahti E and Pasquale EB: Replacing two conserved tyrosines of the EphB2 receptor with glutamic acid prevents binding of $\mathrm{SH} 2$ domains without abrogating kinase activity and biological responses. Oncogene 19: 177-187, 2000.

47. Mellitzer G, Xu Q and Wilkinson DG: Control of cell behaviour by signalling through Eph receptors and ephrins. Curr Opin Neurobiol 10: 400-408, 2000

48. Xu Q, Mellitzer G and Wilkinson DG: Roles of Eph receptors and ephrins in segmental patterning. Philos Trans R Soc Lond B Biol Sci 355: 993-1002, 2000.

49. Schoenwaelder SM and Burridge K: Bidirectional signaling between the cytoskeleton and integrins. Curr Opin Cell Biol 11: 274-286, 1999 .

50. Schlaepfer DD and Hunter T: Integrin signalling and tyrosine phosphorylation: Just the FAKs? Trends Cell Biol 8: 151-157, 1998.

51. Schmucker D and Zipursky SL: Signaling downstream of Eph receptors and ephrin ligands. Cell 105: 701-704, 2001.

52. Shi G, Yue G and Zhou R: EphA3 functions are regulated by collaborating phosphotyrosine residues. Cell Res 20: 1263-1275, 2010. 